\title{
Parameter identification of PMSM using EKF with temperature variation tracking in automotive applications
}

\author{
Rachid KERID $^{1}$, Hicham Bourouina ${ }^{2}$, Réda Yahiaoui ${ }^{3}$ \\ ${ }^{1}$ Departement of Electrical and Electronics, Saad Dahlab University Blida1, Algeria \\ ${ }^{2}$ Laboratory FUNDAPL, Faculty of science, University of Blida, BP. 270 09000, Algeria \\ ${ }^{3}$ Femto-ST Institute UMR 6174, Bourgogne Franche-Comte University, Besancon France \\ *E-Mail: r.kerid@ensh.dz, E-Mail: hi.bourouina@gmail.com
}

\begin{tabular}{l} 
Article Info \\
\hline Article history: \\
Received May 30, 2018 \\
Revised Oct 21, 2018 \\
Accepted Oct 26, 2018 \\
\hline Keyword: \\
Permanent Magnet Synchronous \\
Machine (PMSM), \\
Modeling, Identification, \\
Extended Kalman Filter (EKF), \\
Torque control, \\
Temperature variation.
\end{tabular}

\section{Corresponding Author:}

\section{Rachid KERID}

Departement of Electrical and Electronics,

Saad Dahlab University Blida1,

Algeria

E-mail: r.kerid@ensh.dz

\begin{abstract}
Permanent magnet synchronous machine is widely used for electric vehicles traction because of its high power density and its efficiency on a large flux weakening range. This paper focuses in particular on the estimation of PMSM parameters using EKF, we present a study assessing the temperature variations impact on the behavior of PMSM motor, and therefore we propose to estimate the temperature-dependent parameters. The main contribution in this work is an effective method for estimating parameters or their temperature variation, makes it possible to study and to avoid performance degradation by tracking and adapting the parameters in torque observer in order to find the same performance at any temperature and can be also used for thermal monitoring, which allows for better availability of motor, without causing damage, however, the knowledge of degradation mechanisms also gives insight for the design of this machine. Nowadays, there are essentially maps of reference currents according to the torque and speed that are used by car manufacturers and no account is then given of the parameter variations. The effectiveness of the proposed estimation method verified by both simulation and experiment.
\end{abstract}

\section{Introduction}

Permanent magnet (PM) synchronous motors have attracted increasing interest in recent years for industrial drive application such as traction, automobiles, robotics and aerospace technology. Compared with the induction motor drives, the PM motor drives have high efficiency, high steady state torque density and better controllability make them a good alternative in a wide range of industrial application systems. In addition, the availability of low-cost power electronic devices and the improvement of PM characteristics lead to the use of PMSM in electrical motor drive for high performance application with high efficiency [1]-[3].

To obtain more accurate parameters estimation for PMSM, many different methods have been used in literature, such as neural network, genetic algorithm, Luenberger obsever and EKF which are effective and efficient alternatives for tracking parameter variation, it may be also used for real-time estimation of parameters and state of PMSM [4]-[6]. 
In the other hand, several researches have considered the impact of temperature on parameter, however, the challenge is to avoid degrading motor performance when it heats, adapting online control torque variations of the physical parameters of temperature-dependent motor. In so doing, these physical parameters must be determined on-line, either by direct estimation of these parameters, or by linking their variations with temperature variations [7]-[13].

For this purpose, this work focuses essentially on the online estimation of electric motor parameter using EKF will be then implemented. It will make it possible to determinate the values of the parameters that optimize selected criteria. Therefore, we propose to estimate the temperature-dependent parameters, namely the stator winding resistance and the magnet flux. The knowledge of these parameters or their temperature variations allows indeed avoiding performance degradation by adapting the torque control and makes it possible a thermal monitoring which allows for better availability of motor, without risk of damage.

The remainder of the paper is organizing as follow:

First, the dynamic model of PMSM is described in section 2. Then, development of EKF algorithm is described in section 3. Section 4 gives the multiparameter identification of PMSM using EKF and simulation result. Then the knowledge of these parameters or their temperature variation and its impact on the behavior of PMSM is presented in section 5. Finally the effectiveness of the proposed estimation method is verified by both simulation and experiment.

\section{DQ model for PMSM}

The electrical diagram of permanent magnet synchronous motor is given in Figure 1. It is diagram of single phase, where $R_{\mathrm{s}}$ is stator resistance, $L_{\mathrm{s}}$ is stator inductance. The permanent magnets of the rotor aligned with the rotor axis generate magnetic flux $\psi_{f}$, thus the stator induced voltage $U_{E}$ which has opposite mind, than supply voltage $U_{s}$.

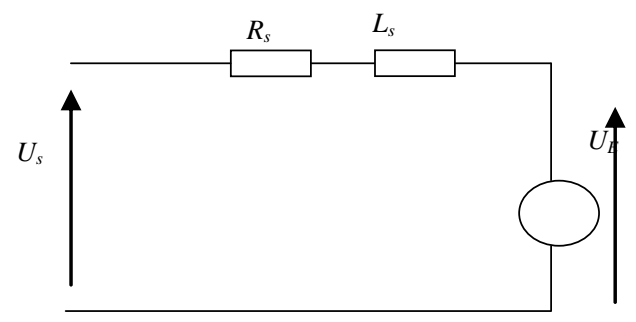

Figure 1. Electrical diagram of PMSM

In order to obtain the model of permanent magnet synchronous motor, we will go from electrical diagram form Figure1.

The adopted assumptions are [14], [15]:

- Feeding voltage has harmonic wave

- Values of stator windings $R$ and $L$ are same for all winding and there are constant.

- Course of magnetic induction $B$ is constant in the air-gap.

- Magnetic current is linear and losses in iron are ignored.

- Induced voltage has harmonic wave.

After park transformation, PMSM equations become:

$$
\begin{aligned}
v_{d q} & =R s\left(i_{d q}\right)+\frac{d}{d t}\left(\psi_{d q}\right)+p \Omega\left[\begin{array}{cc}
0 & -1 \\
1 & 0
\end{array}\right]\left(\psi_{d q}\right) \\
\psi_{d q} & =\left[\begin{array}{cc}
L_{d} & 0 \\
0 & L_{q}
\end{array}\right]\left(i_{d q}\right)+M_{0}\left[\begin{array}{c}
-1 \\
0
\end{array}\right] i_{f}
\end{aligned}
$$

Where $V_{d q}, \psi_{d q}$ and $i_{d q}$ are the components of stator voltage, flux and current in the $d-q$ frame respectively. 


$$
v_{d q}=R s\left(i_{d q}\right)+\left[\begin{array}{cc}
L_{d} & 0 \\
0 & L_{q}
\end{array}\right] \frac{d}{d t}\left(i_{d q}\right)+p \Omega\left[\begin{array}{cc}
0 & -L_{q} \\
L_{d} & 0
\end{array}\right]\left(i_{d q}\right)+p \Omega\left[\begin{array}{c}
0 \\
\psi_{f}
\end{array}\right]
$$

Where $\psi_{f}=M_{0} i_{f}$ is permanent magnet flux.

New model for parameters identification of nonsalient pole MSAP is given as follow [19]:

$$
\left[\begin{array}{l}
v_{d} \\
v_{q}
\end{array}\right]=\left[\begin{array}{cccc}
i_{d} & \left(\frac{d i_{d}}{d t}-p \Omega i_{q}\right) & p \Omega & 0 \\
i_{q} & \left(p \Omega i_{d+} \frac{d i_{q}}{d t}\right) & 0 & p \Omega
\end{array}\right]\left[\begin{array}{c}
R_{s} \\
L \\
0 \\
E
\end{array}\right]
$$

\section{Extended Kalman filter algorithm (EKFA)}

The EKF approach is an optimal recursive estimation algorithm based on the least-square method for non- linear systems, which can be estimating the states of dynamic nonlinear structure. However, it is an optimal estimator used for computation of the conditional mean and probability distribution of covariance of the state of a nonlinear stochastic structure under uncorrelated Gaussian and measurement noise.

In addition, the EKF algorithm can be applied to estimate state variables when the state models are nonlinear.

Nonlinear discrete models with white noise are given as follows [16]-[18]:

-Prediction step:

$$
x\left(\frac{k+1}{k}\right)=f\left(x \cdot\left(\frac{k}{k}\right), u(k)\right)
$$

This step helps to construct a first estimation of the state vector at time $k+1$, it then seeks to determine its variance.

$$
P\left(\frac{k+1}{k}\right)=f(k) P(k) F(k)^{T}+Q
$$

With:

$$
F(k)=\frac{\partial f(x(k), u(k))}{\partial x^{T}(k)}
$$

-Correction step:

By minimizing the variance of the error, the following expressions are obtained:

- Kalman filter's gain:

$$
K(k+1)=P\left(\frac{k+1}{k}\right) \cdot H(k)^{T}\left(H(k) P\left(\frac{k+1}{k}\right) H(k)^{T}+R\right)^{-1}
$$

With:

$$
H(k)=\frac{\partial h(x(k))}{\partial x(k)}
$$

.Errors covariance matrix:

$$
P((k+1) /(k+1))=P((k+1) / k-K(k+1) H(k) P((k+1) / k)
$$

- State vector estimation at time $\mathrm{k}+1$ :

$\hat{x}(k+1) /(k+1)=\hat{x}(k+1 / k)+K(k+1)(Y(k+1)-H(\hat{x}(k+1) / k))$ 
Where:

$Q$ and $R$ are independent from the system state.

\section{Parameter identification of PMSM using EKF}

We can consider parameter identification of PMSM as a system optimization problem. The principal of identification is to search all parameters that minimize the error between the output of the theoretical model and the actual system. The optimization algorithm used for parameter identification contributes to obtain accurate results, where the model of PMSM can be presented as the form of differential equations which is as follows [6], [20]-[23]:

$$
\begin{aligned}
& \dot{x}=f(p, x(t), u(t)) \\
& y(t)=g(p, x), .
\end{aligned}
$$

where $\mathcal{x}(t)=\left(i_{d}, i_{q}\right)$ is the state vector, $V(t)=\left(V_{d}, V_{q}\right)$ is the system input vector, $p=\left(R_{s}, L_{d}, L q, \psi\right)$ is the parameter vector to identify, $\mathcal{y}(t)$ is the measurable output vector, and $f(p, x(t), u(t))$ and $g(p, x)$ can be either linear or nonlinear system. The aim of parameter estimation is to identify the unknown parameter vector $p$ as precisely as possible. The tracking model of the system is described as follows:

$$
\begin{aligned}
& \hat{\dot{x}}=f(\hat{p}, \hat{x}(t), u(t)) \\
& \hat{y}(t)=g(\hat{p}, \hat{x}), .
\end{aligned}
$$

Components and the flow chart of the EKF parameters identification are illustrated in Figure 2.

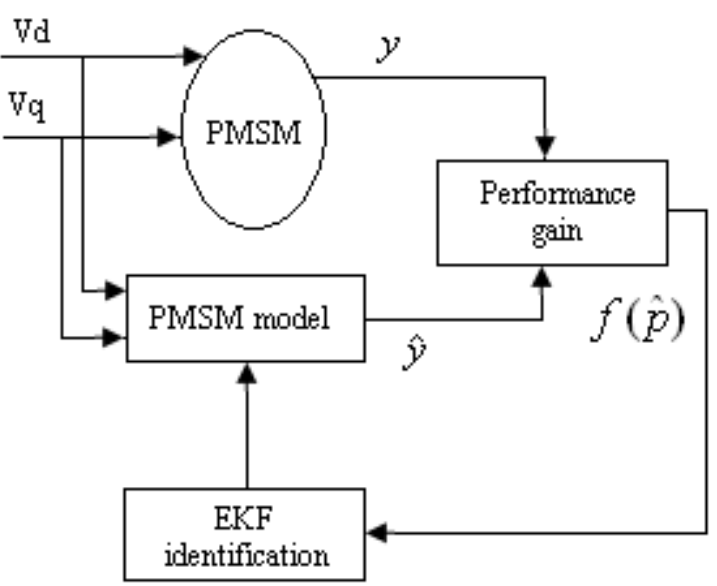

(a) : Components of EKF parameters identification.

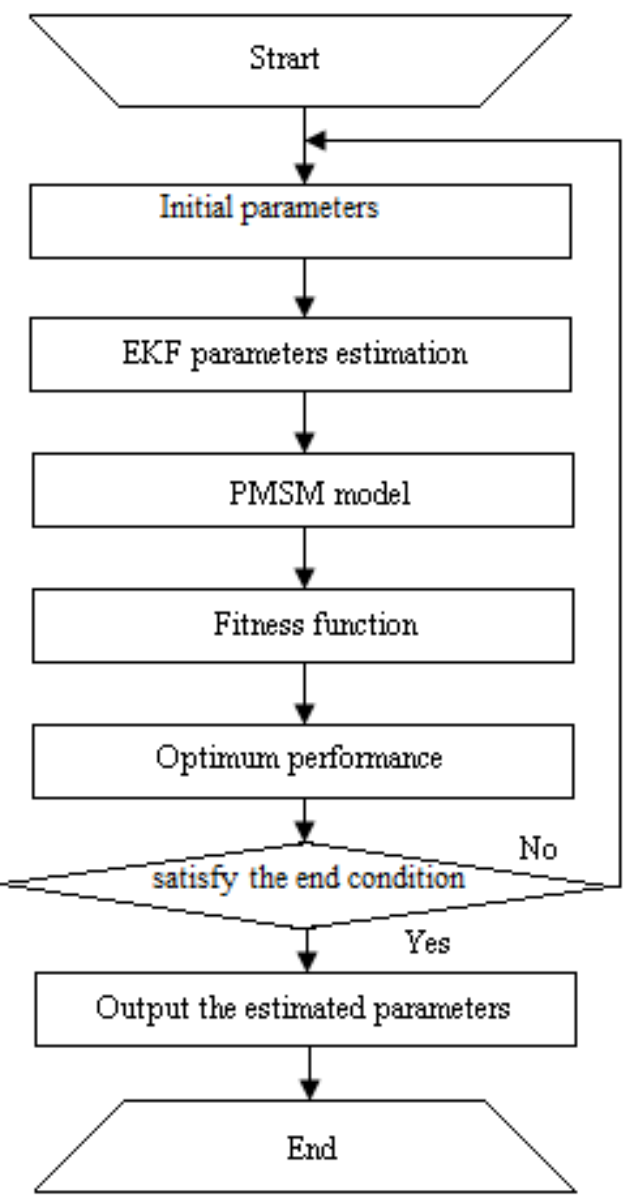

(b) : Flow chart of EKF parameters identification. 
Figure 2. EKF parameters identification

\section{Influence of temperature-dependent parameters on the behavior of PMSM}

To ensure the best possible torque in control, it was necessary to know at all times the values of the motor parameters, among these, both depend on the motor temperature which undergo changes in the course of a path, namely the resistance of the stator windings via the resistivity of copper and the flux of the permanent magnets demagnetize with increase in temperature. The inductance value, it does not depend on temperature. The challenge is to avoid degrading motor performance when it heats, adapting online control torque variations of the physical parameters of temperature-dependent motor. To do this, these physical parameters must be determined on-line, either by direct estimation of these parameters, or by linking their variations with temperature variations [9]-[13]. Indeed, by default, the torque control is set using the values at rated temperature $\left(20^{\circ} \mathrm{C}\right)$ parameters as indicated in figure 5 .

The optimization problem (Figure 2) is therefore biased because the reference currents resulting, optimum at nominal temperature, are no longer at the actual temperature. The supplied torque is less than the required torque, and the same applies to the power output. In particular, by operating area limit the power and maximum torque are no longer accessible. Thus, to provide the power and torque required at any point of operation, and especially to maintain speed, power and maximum torque available, it is necessary to feed the optimization problem with the correct parameter values.

To solve this problem, an adaptive torque control to find the same performance at any temperature. Nowadays, there are essentially maps of reference currents $\mathrm{I}_{\mathrm{d}}{ }^{*}$ and $\mathrm{I}_{\mathrm{q}}{ }^{*}$ according to the torque and speed that are used by car manufacturers and no account is then given of the parameter variations.

\section{Application results and discussion}

In order to demonstrate the performance of EKF applied to PMSM parameter estimation, the simulations are realized using Matlab/Simulink. The fitness function is optimized using EKF to search a good result for identification of PMSM electrical parameters such as stator resistance, inductances, and rotor flux linkage as shown in Figure 3. The values of nominal and estimated parameters are given in Table 1. In figure 3(a) the estimated is quite close to the actual resistance $(3.478 \Omega)$ and to the actual inductance $(0.0125 \mathrm{H})$ in figure 3 (b), but the rotor flux linkage can be precisely estimated if the winding resistance and inductance are accurately estimated. As the experimental result shows that the estimated winding resistance and inductance has a high precision, therefore it is shown that the estimated rotor flux linkage by EKF is accurate $(0.015 \mathrm{~Wb})$ in figure 3(c). As consequence, the proposed method has high performance in accurately tracking the variation of parameters

In the other hand, we were compared EKF with particle filtering (PF) which is a Monte Carlo simulation based nonlinear filtering algorithm. From experiments, we know that the EKF requires a good Gaussian estimate of the initial state and an evaluation of measurement noise to converge and PF does not perform well with small number of particles, the average variance and the complexities of the filtering methods in a recursive filtering algorithm and PF has a little longer running time than EKF, but its variance is the smallest as shown in ref. [22].

From the simulations performed, it can be seen that the EKF proposed for estimation parameters is more consisted and convergent than the Monte Carlo algorithm.

And the results obtained were also compared with least square and Newton Raphson methods showing more accurate performance [24]-[27].

In addition, we found that our results, in terms of precision were remarkably similar those predicted by Liu et al in ref. [9]. 
Table 1. Electrical parameters of PMSM.

\begin{tabular}{lll}
\hline Parameters & EKF estimation & Nominal parameter \\
\hline $\mathrm{R}_{\mathrm{s}}(\Omega)$ & 3.4782 & 3.4 \\
$\mathrm{~L}=\mathrm{L}_{\mathrm{d}}=\mathrm{L}_{\mathrm{q}}(\mathrm{H})$ & 0.0125 & 0.0121 \\
$\psi_{f}(\mathrm{~Wb})$ & 0.0150 & 0.013 \\
& & \\
\hline
\end{tabular}

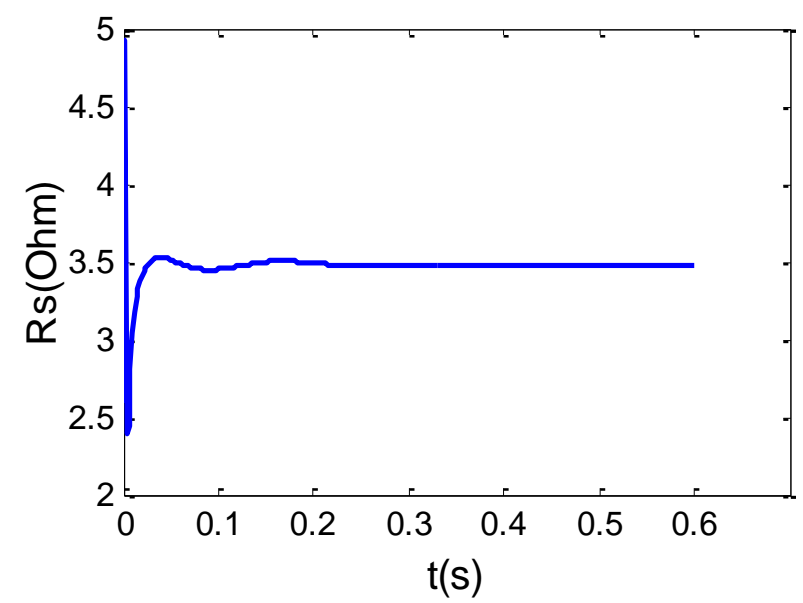

(a): Estimated of stator resistance Rs

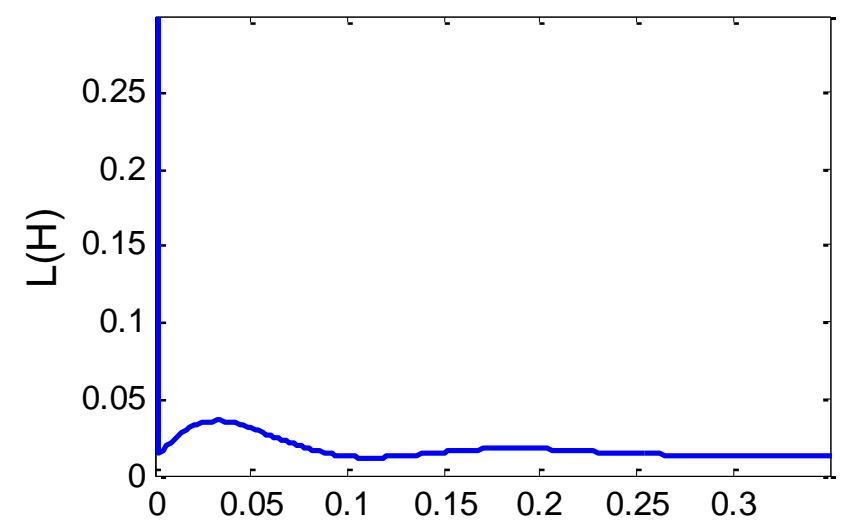

$\mathrm{t}(\mathrm{s})$

(b): Estimated of inductance $\mathrm{L}=\mathrm{L}_{\mathrm{d}}=\mathrm{L}_{\mathrm{q}}$

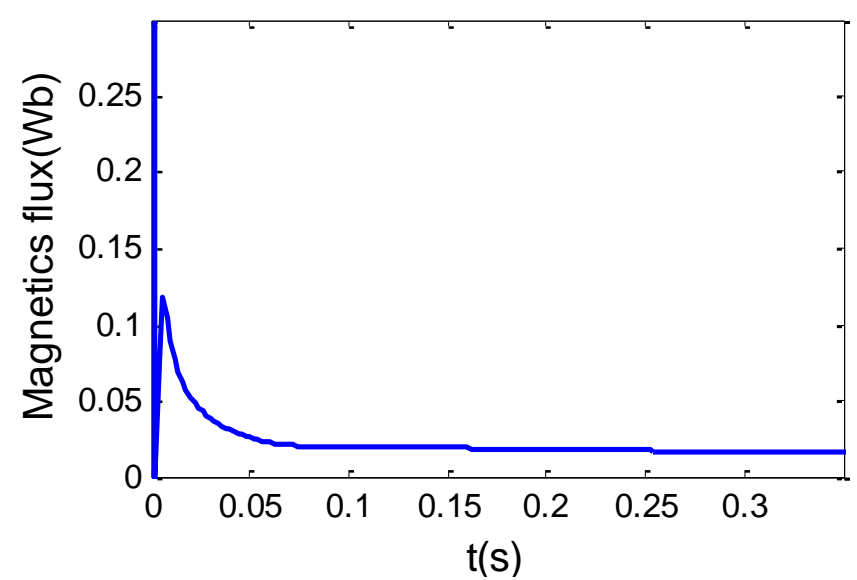


(c) : Estimated of magnetic flux $\psi_{f}$

\subsection{Experiment}

Figure 3. EKF parameters identification

In order to verify the effectiveness of the suggested estimation method, experiments are realized for this purpose. The experimental results were obtained on a PMSM fed by current control drive, mechanically coupled to DC motor as its load and the DSP based hardware are presented in Figure 4, technical character for PMSM is given to table 2.

In the experiment, the motor rotates at its nominal speed where data including $d q$-axis current, $d q$-axis voltage and electrical speed are stored. During the identification process, the data are sent to the computer located on the same platform to determine iteratively the parameter values of vector $P$.

Optimization process used in this application to identify parameters is shown in Figure 3. The identification result is similar to the simulation result described previously given in table 1 .

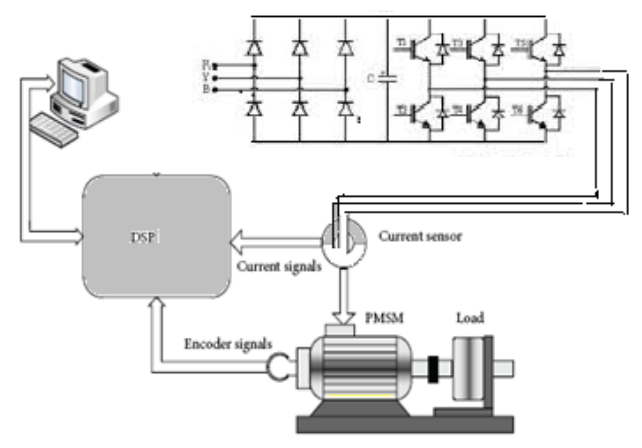

Figure 4. Configuration of the experimental system.

Table 2. PMSM specification.

\begin{tabular}{lc}
\hline Electrical parameters & Mechanical parameters \\
\hline Rated power $=1.38 \mathrm{~kW}$ & Rated speed $=3000 \mathrm{rpm}$ \\
Rated voltage $=220 \mathrm{~V}$ & $\mathrm{~J}=0.0011 \mathrm{Kg} \cdot \mathrm{m}^{2}$ \\
Nominal curtent $=7.1 \mathrm{~A}$ & $\mathrm{f}=5.10^{-5} \mathrm{mN}(\mathrm{rd} / \mathrm{s})$ \\
$\psi_{f}=0.013$ & $P=2$ \\
\end{tabular}

Illustrate the performance degradation induced to non-adaptive control online to changes in temperature dependent parameters, and inversely performance gain in case of adaptation is given in Figure 5 (Simulation results).

Therefore, at nominal temperature, control is fulfilling its role and provides the required torque. However, if the temperature is different, the values of physical parameters of the motor used for the torque control are different from their actual values as shown in references [9], [18].

The supplied torque is less than the required torque as indicated in figure 5(a), the PMSM mechanical speed obtained by EKF remains fixed despite the degradation of performance due to the increase in temperature as mentioned in figure $5(\mathrm{~b})$.

The performance of the EKF at low speed is not satisfactory resulting in high speed at transitions. However, the measured speed has shown that the performance of the EKF is satisfactory at medium and high speed operations as mentioned in references [8]-[11]. Figure 5(c) has indicated that both lower and upper limits for the mechanical characteristic with constant speed command, increasing temperature and varying 
load torque with respect to the maximum value. Figure 5(d) shows that the global efficiency is negatively affected when the PMSM operates at high speed and contribute even more to the decrease of machine efficiency.

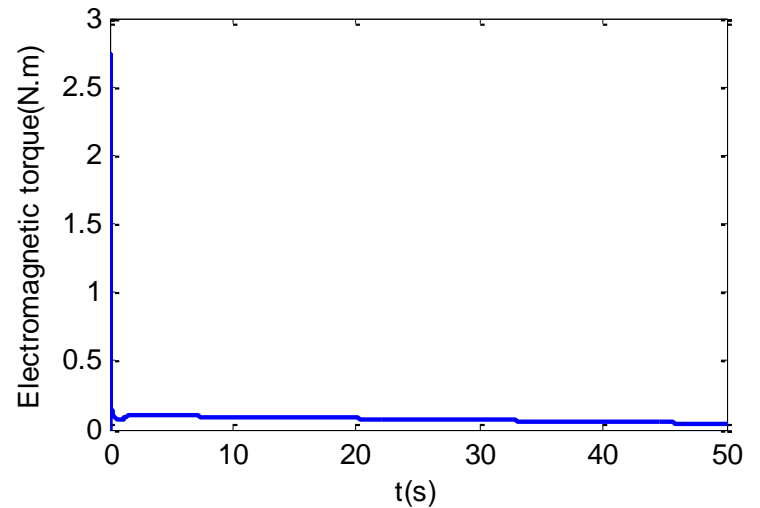

(a)

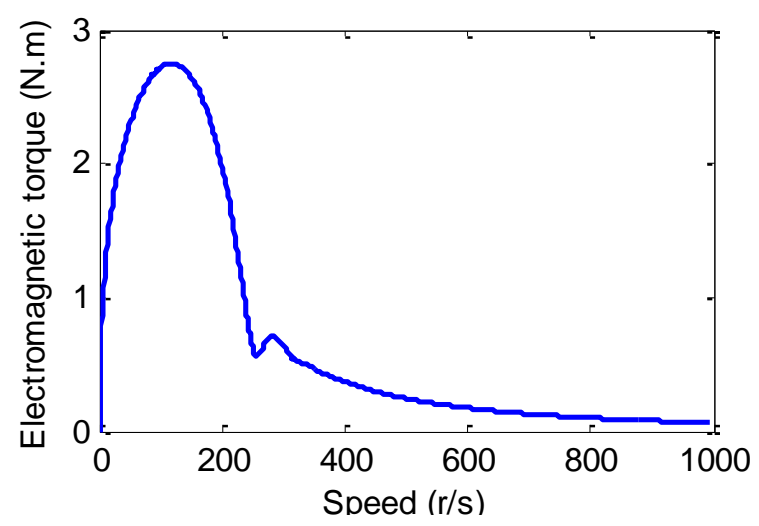

(c)

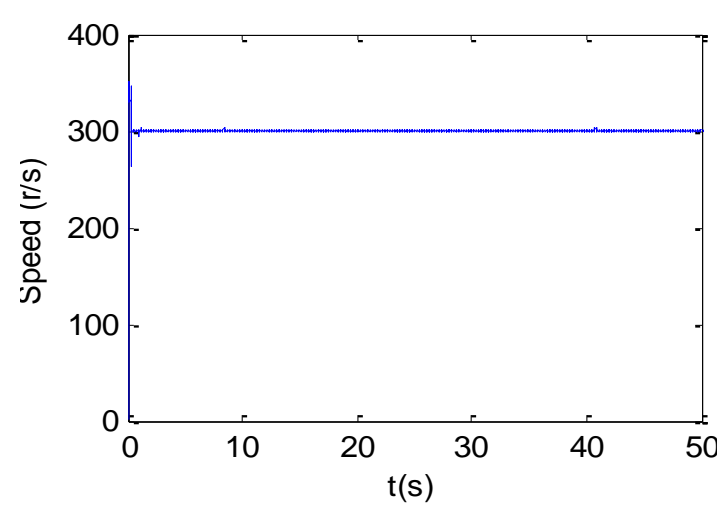

(b)

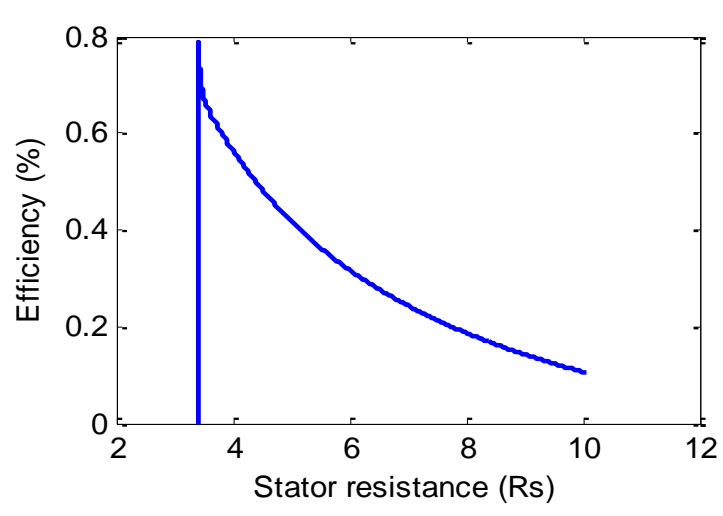

(d)

Figure 5. Simulation result: Impact of temperature on PMSM

(a): Electromagnetic torque, (b): Speed, (c): mechanical characteristic, (d): Efficiency versus stator resistance

\section{Conclusion}

The efficiency of a PMSM, which can be used in electric vehicle applications, is affected by some parameters. In this paper, we are proposed to estimate the temperature-dependent parameters, namely the winding resistance and the magnet flux. The knowledge of these parameters or their temperature variations makes it possible to avoiding performance degradation by tracking and adapting the parameters in the torque control and allows a thermal monitoring for motor availability improvement without causing damage. Also, it has been evaluated the total influence for behavior PMSM, both simulation and experiment results are provided to verify the effectiveness of the proposed method. By comparison with other different algorithms, we have shown that the EKF has better optimization capability and has good convergence in simultaneously estimating PMSM electrical parameters such as stator resistance, $d q$ axis inductances, and rotor flux linkage, as the proposed method is used for nonsalient pole PMSM $(L d=L q)$.

To perform experimental analysis, in future application, we try to utilize the design of Experiments (DOE) technique, which is statistical tool used in various types of system, process and product design, development and optimization. It can be considered as a fundamental method employed in various situations such as design for comparing optimization and robust parameter estimation, variable screening and transfer function identification. 


\section{Acknowledgment}

This work was supported by the Algerian PNR domiciled in FUNDAPL Laboratory, University of Blida (Algeria)

\section{REFERENCES}

[1] S. Ichikawa, M.Tomita, S. Doki, and S. Okuma. "Sensorless control of permanent-magnet synchronous motors using online parameter identification based on system identification theory," IEEE Transactions on Industrial Electronics, vol. 53, no. 2, pp.363-372 (2006).

[2] D. Xu, J. Liu, S., Zhang, H. Wei, Elimination of Low-speed Vibration in Vector-controlled Permanent Magnet Synchronous Motor by Real-time Adjusted Extended Kalman Filter. Electric Power Components and Systems, 43(20), 2276-2287 (2015).

[3] R. Olfati-Saber." Distributed Kalman filter with embedded consensus filters. 44th IEEE Conference on Decision and Control”, 2005 and 2005 European Control Conference (CDC-ECC '05), pages 8179-8184 (Dec. 2005).

[4] O. Gursoy, M. H. Sharif, Parallel Computing for Artificial Neural Network Training. Periodicals of Engineering and Natural Sciences, 6(1), 1-10(2018).

[5] A. A. Hassan, A. M. Kassem, Modeling, Simulation and Performance Improvements of a PMSM Based on Functional Model Predictive Control. Arabian Journal for Science \& Engineering (Springer Science \& Business Media BV), 38(11) (2013).

[6] R. Arulmozhiyal and K. Baskaran, "Implementation of a Fuzzy PI Controller for Speed Control of Induction Motors Using FPGA," Journal of Power Electronics, vol. 10, pp. 65-71 (2010).

[7] O. Lutfy, Wavelet Neural Network Model Reference Adaptive Control Trained by a Modified Artificial Immune Algorithm to Control Nonlinear Systems. Arabian Journal for Science \& Engineering (Springer Science \& Business Media BV), 39(6) (2014).

[8] M.Zeraoulia et al. Diallo, "Electric Motor Drive Selection Issues for HEV Propulsion systems: A comparative study," IEEE Trans on Vehicular Technology, Vol.55, No.6, pp1756-1764 (2006).

[9] L. Liu, W. X. Liu, and D. A. Cartes. Permanent magnet synchronous motor parameter identification using particle swarm optimization. International Journal of Computational Intelligence Research, 4(2), 211-218 (2008).

[10] K. Liu, Q. Zhang, J. Chen, Z.Q. Zhu and J. Zhang. Online multiparameter estimation of nonsalientpole PM synchronous machines with temperature variation tracking. IEEE Transactions on Industrial Electronics, 58(5), 1776-1788 (2011).

[11] R. Delpoux, M. Bodson, and T. Floquet. "Parameter estimation of permanent magnet stepper motors without mechanical sensors," Control Engineering Practice, vol. 26, pp. 178-187, May 2014.

[12] S.-B. Lee, T. G. Habetler, R. G. Harley, and D. J. Gritter. "An evaluation of modelbased stator resistance estimation for induction motor stator winding temperature monitoring," Energy Conversion, IEEE Transactions on, 17(1):7-15 (2002).

[13] Z. YILMAZ, M. OKSAR, F. BASCIFTCI, Multi-Objective Artificial Bee Colony Algorithm to Estimate Transformer Equivalent Circuit Parameters. Periodicals of Engineering and Natural Sciences (PEN), 5(3), (2017).

[14] G.terorde, "Sensorless control of a permanent magnet synchronous motor for PV-powered water pump systems using the extended Kalman filter," Ninth international Conference on Electrical Machine and Drives, conference Publication N0486,IEE,1999.

[15] K. T. Chau, C. C. Chan, and L. Chunhua, "Overview of permanent-magnet brushless drives for electric and hybrid electric vehicles," IEEE Trans.Ind. Electron. vol. 55, no. 6, pp. 2246-2257, Jun. 2008..

[16] K. I. Laskaris and A. G. Kladas, "Internal permanent-magnetmotor design for electric vehicle drive," IEEE Trans. Ind. Electron., vol. 57, no. 1,pp. 138-145, Jan. 2010.

[17] J. O. Estima and A. J. M. Cardoso, "Performance analysis of a PMSM drive for hybrid electric vehicles," in Proc. Int. Conf. Elect. Mach., Sep. 6-8, 2010, pp. 1-6

[18] N. Urasaki, T. Senjyu, and K. Uezato, "A novel calculation method for iron loss resistance suitable in modeling permanent-magnet synchronous motors," IEEE Trans. Energy Convers., vol. 18, no. 1, pp.41-47 
[19] N. Henwood, "Online estimation of electric motor parameters for tracking of its components temperature in automotive application," PhD. thesis, NORMAL SCHOOL SUPERIOR PARIS MINE , France, 2014.

[20] F. khatounian, "Contribution to modeling, identification and control of a haptic interface with one degree of freedom driven by a permanent magnets synchronous machine," PhD. thesis, NORMAL SCHOOL SUPERIOR CACHAN, France, 2006.

[21] S. Ma, P. Wu, J. Ji, X. Li, Sensorless control of salient PMSM with adaptive integrator and resistance online identification using strong tracking filter. International Journal of Electronics, 103(2), 217-231 (2016).

[22] S. Kurak, M. Hodzic, Control and Estimation of a Quadcopter Dynamical Model. Periodicals of Engineering and Natural Sciences, 6(1), 63-75, (2018).

[23] X. Deng, J. Lu, R. Yue, and J. Zhang., A strong tracking particle filter for state estimation. In Natural Computation (ICNC), 2011 Seventh International Conference on (Vol. 1, pp. 56-60). IEEE. (2011, July).

[24] Y. Yi, W. X. Zheng, C. Sun, and L. Guo, DOB Fuzzy Controller Design for Non-Gaussian Stochastic Distribution Systems Using Two-Step Fuzzy Identification. IEEE Transactions on Fuzzy Systems, 24(2), 401-418, (2016).

[25] M. Klingajay and N. I. Giannoccaro, Comparison between least square \& Newton Raphson for estimation parameters of an autonomous threaded fastenings. In Industrial Technology, 2003 IEEE International Conference on (Vol. 1, pp. 163-168). IEEE (2003, December).

[26] H. O. Ozer, Y. Hacioglu, N. Yagiz, Controlling the Building Model Using High Order Sliding Mode Control Optimized by Multi Objective Genetic Algorithm. Periodicals of Engineering and Natural Sciences (PEN), 5(3), (2017).

[27] B. Durakovic, Design of Experiments Application, Concepts, Examples: State of the Art. Periodicals of Engineering and Natural Sciences (PEN), 5(3) (2017).

\section{BIBLIOGRAPHY OF AUTHORS}

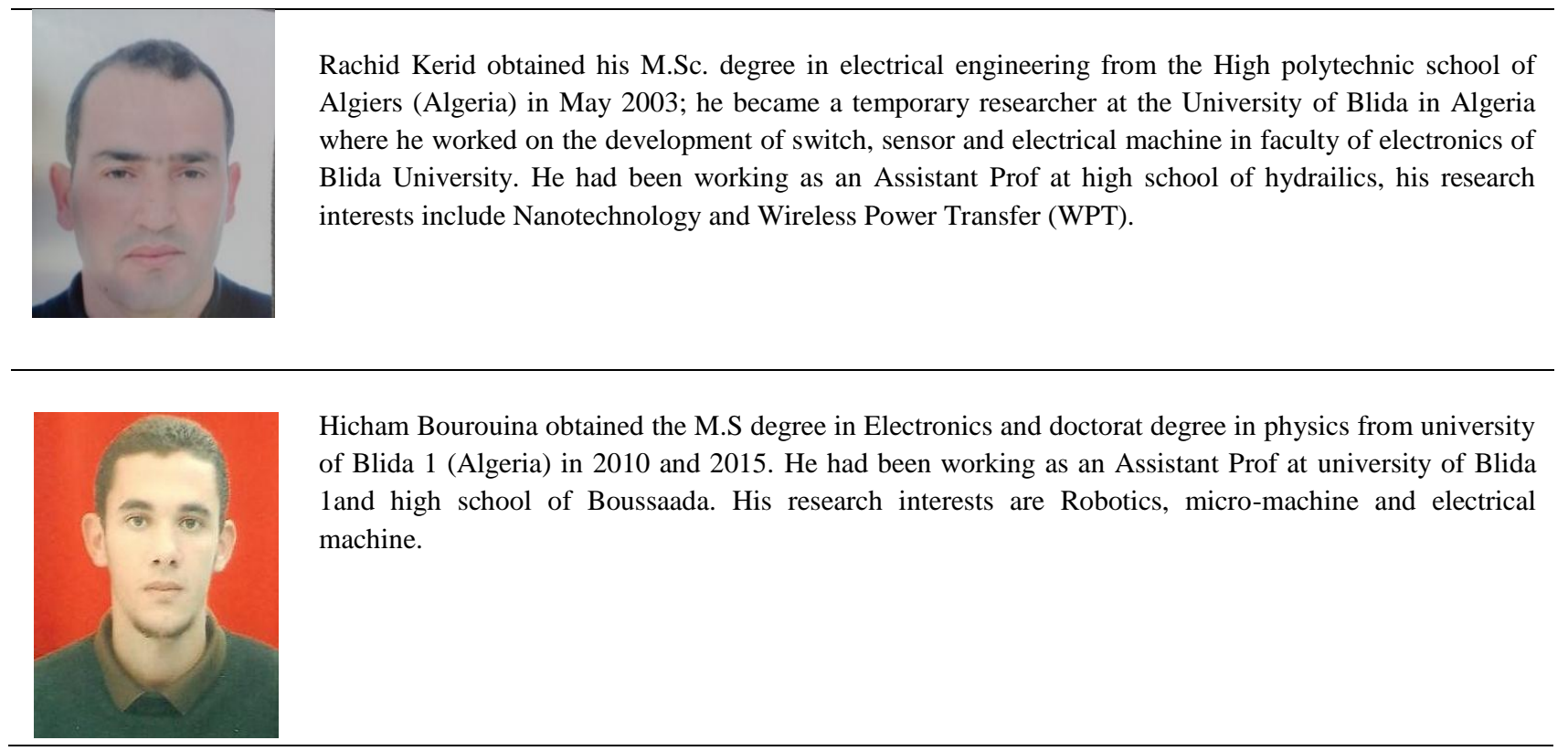


Réda Yahiaoui received the M.S. degree in Electronics Sensors and Integrated Circuits - Option Microwaves and Fast Electronic in 1998, and the $\mathrm{PhD}$ degree in engineering science in 2002, from the University Paris-XI, Orsay, France. He works as Research Engineer in Electronics and project Manager in UAV development until 2005. Since September 2005, he works as assistant professor in the Micro Nano Sciences \& Systèmes (MN2S) department of FEMTO-ST Institute, Besançon, France. His main interests are in BioMEMS devices for Bacteria detection: design, modelling, microfabrication and embedded electronics. 